www.jmscr.igmpublication.org

Index Copernicus Value: 79.54

ISSN (e)-2347-176x ISSN (p) 2455-0450

crossrefDOI: https://dx.doi.org/10.18535/jmscr/v7i1.122

\title{
Injury Pattern among Fatal Road Traffic Accident Cases at Indira Gandhi Institute of Medical Sciences Mortuary
}

\author{
Authors \\ Mukesh Prasad $^{1}$, Aman Kumar ${ }^{2 *}$, Arvind Prasad ${ }^{3}$, Sanjeev Kumar $^{4}$, Nikhil Goel ${ }^{5}$ \\ ${ }^{1}$ Medical Officer; ${ }^{2}$ Additional Professor, ${ }^{4}$ Associate Professor, ${ }^{5}$ Junior Resident (Academic) \\ Department of F.M.T., Indira Gandhi Institute of Medical Sciences, Patna, India \\ ${ }^{3}$ Professor, Department of FMT, Narayan Medical College and Hospital, Jamuhar \\ *Corresponding Author \\ Aman Kumar \\ Email:dramankumarfmt@yahoo.in
}

\begin{abstract}
Introduction: Road traffic injuries are recognized globally as a major public health problem, for being one of the leading causes of deaths, disabilities and hospitalization, imposing huge socio-economic costs. In case of India, road injuries is one of the top four leading causes of death and health loss among persons of age group 20-60 years. It has been estimated that without immediate effective intervention, Globally it will become the fifth leading cause of death by 2030 resulting in an estimated 2.4 million fatalities annually. The aim of present study is to study pattern of injuries, to find out cause of death and demographic distribution of fatal RTA cases in IGIMS, Bihar.

Materials and Methods: In this observational study carried out at Department of FMT, IGIMS, Patna, autopsies of RTA cases were analysed for type, pattern and distribution of injuries, body parts involved and cause of death.

Results: A total of 248 cases were brought for medico-legal autopsy into the department during the study period of which 135 (54.43\%) cases were of victims of road traffic accidents. 118(87.40\%) of them were male. Major cause of death was observed to be polytrauma (45.93\%) followed by head injury which accounts for $40.74 \%$ of cases. Abrasion was most common injury pattern seen in 121 cases.

Conclusion: Strict licensure procedure along with minimum level of education regarding road safety should be imparted. The present study emphasizes the need of compulsory implementation of helmet wearing for motorcyclist.

Keywords: Injuries, Globally, Disabilities, Intervention, Fatal.
\end{abstract}

\section{Introduction}

Road Traffic Accident (RTA) can be defined as, 'An event that occurs on a way or street open to public traffic; resulting in one or more persons being injured or killed, where at least one moving vehicle is involved. Thus, RTA is a collision between vehicles; between vehicles and pedestrians; between vehicles and animals; or between vehicles and any obstacles'. Road traffic accidents are a human tragedy ${ }^{[1]}$. They involve high human suffering and socioeconomic costs in terms of premature deaths, injuries, loss of 
productivity etc ${ }^{[2]}$. The world's first road traffic car fatality occurred on 31st August 1869 in Ireland killing a renowned scientist Mary Ward ${ }^{[3]}$. Incidences of RTA have been increasing at an alarming rate throughout the world ${ }^{[4]}$. Road traffic injuries are recognized, globally, as a major public health problem, for being one of the leading causes of deaths, disabilities and hospitalization, imposing huge socio-economic costs. In case of India, road injuries is one of the top four leading causes of death and health loss among persons of age group 15-49 years. During the calendar year 2016 , the total number of road traffic accidents is reported at 4,80,652 causing injuries to 4,94,624 persons and claiming $1,50,785$ lives in the country. This would translate, on an average, into 1317 accidents and 413 accidental deaths taking place on Indian roads every day; or 55 accidents and 17 deaths every hour ${ }^{[5]}$. Continuous growth in number of motor vehicles, increase in population and poor access to health care are some of the important factors in fatalities due to vehicular accidents ${ }^{[6]}$. No age group is immune from the RTA, but the most vulnerable victims are the younger people between 21 to 45 years of age ${ }^{[7]}$. It has been estimated that without immediate effective intervention, Road Traffic Accident will become the fifth leading cause of death by 2030 resulting in an estimated 2.4 million fatalities annually ${ }^{[8,9]}$. The aim of present study is to study pattern of injuries, to find out cause of death and demographic distribution of fatal RTA cases in IGIMS, Bihar.

\section{Materials and Methods}

An observational study was carried out between $25 / 12 / 2015$ to $24 / 06 / 2017$ in department of F.M.T, I.G.I.M.S, Patna, Bihar. All cases of RTA brought for autopsy at mortuary of IGIMS, Patna within the study period were included. Mutilated and decomposed bodies were excluded from the study. The demographic characters related to victim's accidents were gathered from police records or by history of the police officials, or relatives and friends of deceased accompanying dead bodies. The pathological features of these cases as type, pattern and distribution of injuries, body parts involved, and cause of death were noted at the actual autopsy examination of victim and analyzed.

\section{Results}

A total of 248 cases were brought for medicolegal autopsy into the department during the study period. Out of total of 248 autopsies done, 135 (54.43\%) were victims of road traffic accidents. Table 1 shows that out of 135 medicolegal autopsies during study period $118(87.40 \%)$ were of male. Incidence of death due to RTA was $52.59 \%$ in age group $21-40 y r s$ and $6.67 \%$ in more than $60 \mathrm{yrs}$ of age group. Table 2 shows that major cause of death due to injuries were polytrauma $(45.93 \%)$ followed by head injury which accounted for $40.74 \%$ of total deaths. Table 3 shows that abrasion was the most common injury pattern seen in 121(89.62\%) cases followed by laceration which was seen in $102(75.55 \%)$ cases.

Table 1- Showing age and sex distribution in RTA victims

\begin{tabular}{|l|c|c|c|}
\hline $\begin{array}{l}\text { Age(in } \\
\text { years) }\end{array}$ & Male (\%) & Female (\%) & Total (\%) \\
\hline $0-20$ & $17(12.59)$ & $01(0.74)$ & $18(13.33)$ \\
\hline $21-40$ & $60(44.44)$ & $11(8.15)$ & $71(52.59)$ \\
\hline $41-60$ & $32(23.70)$ & $05(3.71)$ & $37(27.41)$ \\
\hline$>60$ & $09(6.67)$ & $00(00)$ & $09(6.67)$ \\
\hline Total & $118(87.40)$ & $17(12.60)$ & $135(100)$ \\
\hline
\end{tabular}

Table 2- Showing cause of death in road traffic accident (RTA) cases

\begin{tabular}{|l|c|c|}
\hline Cause of death & Cases & Percentage \\
\hline Head injury & 55 & 40.74 \\
\hline Chest injury & 11 & 8.15 \\
\hline Abdominal injury & 05 & 3.70 \\
\hline Septicemic Shock & 02 & 1.48 \\
\hline Polytrauma & 62 & 45.93 \\
\hline Total & 135 & 100 \\
\hline
\end{tabular}

Table 3- Showing cause of death in road traffic accident (RTA) cases

\begin{tabular}{|l|c|c|}
\hline Injuries & Cases & Percentage \\
\hline Abrasion & 121 & 89.62 \\
\hline Laceration & 102 & 75.55 \\
\hline Multiple superficial injuries & 14 & 10.37 \\
\hline Crush injuries & 8 & 5.92 \\
\hline
\end{tabular}




\section{Discussion}

Road accidents are one of the major cause of mortality and morbidity throughout the world. The growth of road transportation has caused an Increase in road traffic accidents especially in South-east Asian countries like India that has serious negative social, economic and health sequel. Our study shows that incidence of RTAs is of male preponderance. Out of 135 cases of death from road traffic accident there were 118 $(87.40 \%)$ males. This prevalence of males over females has also been recorded by various authors $[10,11$,$] . It may be because in our society, males are$ usually the main earner of the family and go outdoors for the living. In the present study, the highest number of RTA victims belonged to younger age group 21 to 40 years $(52.59 \%)$ which is in accordance with the studies done in the past $^{[12]}$. In our study, majority of cases 62 (45.93\%) died due to polytrauma followed by head injury 55 (40.74\%) which is in contrast with the study done by Bhengra $\mathrm{A}$ at $\mathrm{al}^{[13]}$. Abrasion $(89.62 \%)$ and laceration $(75.55 \%)$ were the commonest types of injuries among the injuries noted in this study. Similar results were also observed by other studies done in the past ${ }^{[14]}$.

\section{Conclusion}

It is recommended that strict licensure procedure should be followed and minimum level of education regarding road safety should be imparted. Policies are also needed to protect passengers in commercially operated passengerferrying buses, minibuses and trucks because these vehicles carry a higher risk of being involved in fatal crashes. Stricter legislation should be adopted in dealing with rash, negligent driving and driving under the influence of alcohol. Compulsory implementation of helmet wearing for motorcyclist needs to be emphasized furthermore. Strict enforcement of road safety regulations and improving emergency medical services may prevent needless deaths and disabilities caused by road traffic collisions is the need of the hour.

\section{References}

1. Ruikar M. National statistics of road traffic accidents in India. J Orthop Traumatol Rehabil 2013;6:1-6.

2. Transport Research Wing, Ministry of Road Transport and Highways Road Accidents in India 2011. New Delhi: Ministry of Road Transport and Highways, Government of India; 2012.

3. Wikipedia; Traffic collision; Available online:

http://en.wikipedia.org/wiki/Traffic_collisi on

4. Singh YN, Bairagi KK, Das KC. An epidemiological study of road traffic accident victims in medicolegal autopsies. JIAFM. 2005;27(3):166-9.

5. Transport Research Wing, Ministry of Road Transport and Highways Road Accidents in India 2016. New Delhi: Ministry of Road Transport and Highways, Government of India; 2017.

6. Kumar A, Lalwani S, Agrawal D, Rautji R, Dogra TD. Fatal road traffic accidents and their relationship with head injuries: An epidemiological survey of five years. The Indian Journal of Neurotrauma. 2008 Dec 1;5(2):63-7.

7. Peden MM, Scurfield R et al. 2004. World report on road traffic injury prevention. Geneva: WHO.

8. Murray CJL, Lopez AD. 1996. The global burden of disease and injury series. Volume I. A comprehensive assessment of mortality and disability from diseases, injuries and risk factors in 1990 and projected to 2020. Geneva :WHO.

9. Binod Kumar Ravi, Nikhil Goel, Binay Kumar,C.S. Prasad, A.K. Chaudhary. Pattern of Injuries in Road Traffic Accidents in Ranchi, Jharkhand: An Autopsy Based Study. Int J Med Res Prof. 2017 Sept; 3(5):115-17. 
10. Gupta S, Deb P K, Moitra R, Chhetri D. Demographic study of fatal cranio-cerebral road traffic injuries in North Bengal region. JIAFM 2007: 29(1); 25-27.

11. Chavali K H, Sharma B. R, Dasari H, Sharma A. Head Injury: The principal killer in RTA. JIAFM 2006: 28 (4); 121 124.

12. Kaul A, Shina S, Pathak YK, Singh A, Kapur AK, Sharma S, Singh S. Fatal RTA, Study of distribution, nature \& type of injury. JIAFM 2005:27(2); 71-76.

13. Bhengra A, Shubhendu K, Korah MK, Guria J. Profile of Death due to Road Traffic Accidents Brought to Rajendra Institute of Medical Sciences, Ranchi from 2013-14. Chest.;9:9.

14. Jha N, Srinivasa DK, Roy G, Jagdish S. Injury pattern among road traffic accident cases: A study from South India. Indian J Community Med. 2003 Apr 1;28(2):84-90. 